Brit. J. vener. Dis. (1955), 31, 188.

\title{
INTRAMUSCULAR TETRACYCLINE (ACHROMYCIN) IN THE TREATMENT OF ACUTE GONORRHOEA IN THE MALE*
}

\author{
BY
}

\author{
MILTON MARMELL AND AARON PRIGOT
}

\author{
From the Departments of Surgery and Pathology, Harlem Hospital, Department of Hospitals, New York
}

Penicillin is used extensively in the routine parenteral treatment of gonorrhoea. At times, however, patients report a history of allergy to this antibiotic. Oral treatment with sulpha drugs and other antibiotics may be used in such cases, but the multiple dose schedule that is usually followed leaves the patient unsupervized when he takes the medication. Often the prescribed directions are not followed ; at times the medication is lost ; and on occasion it is used for purposes other than intended (such as sharing the medication between sex partners, leaving both undertreated). There is thus a need for a parenteral medication other than penicillin in the armamentarium against gonorrhoea.

Recently tetracycline for intramuscular injection $\dagger$ became available. Since excellent results have been obtained in the treatment of gonorrhoea with the oral form (Metzger, Marmell, and Prigot, 1954 ; Marmell and Prigot, 1954), it was deemed advisable to test the efficacy of the intramuscular preparation in this disease. This paper presents our data on the use of this antibiotic in 88 cases of acute gonorrhoea.

\section{Method}

Tetracycline for intramuscular injection is available in vials containing $100 \mathrm{mg}$. of the antibiotic with $40 \mathrm{mg}$. procaine hydrochloride, $46.84 \mathrm{mg}$. magnesium chloride, and $250 \mathrm{mg}$. ascorbic acid. The contents of the vial are readily soluble in distilled water or saline solution. Two ml. of the diluent are added to the vial, thus making a solution containing $50 \mathrm{mg}$. of the antibiotic per $\mathrm{ml}$. We used distilled water in our investigations.

Details of the methods used have been described by Marmell and Prigot (1955). All the patients in this study showed clinical and laboratory (smear and culture) evidence of gonorrhoea. They were considered as cured only if the purulent discharge disappeared and posttreatment smears and cultures were negative, and if there was no relapse during the entire observation period, which was not shorter than 7 days.

Treatment consisted of intramuscular injections of tetracycline in the following dose schedules :

\footnotetext{
* Received for publication May 17, 1955.

+ The trade name of the Lederle Laboratories for the antibiotic tetracycline is Achromycin, and the preparation employed was furnished through the courtesy of that company
}

(a) A single injection of $100 \mathrm{mg}$. of intramuscular tetracycline into the upper outer quadrant of the buttock. Total dose, $100 \mathrm{mg}$.

(b) Two injections of $100 \mathrm{mg}$. each given simultaneously into each buttock. Total dose, $200 \mathrm{mg}$.

(c) Two simultaneous injections of $100 \mathrm{mg}$. into each buttock on 2 successive days. Total dose, $400 \mathrm{mg}$.

Of the 88 cases thus treated only 45 were adequately followed-up after treatment, and these form the basis of this report.

\section{Results}

The results obtained with the various dose schedules are summarized in the Table.

TABLE

INTRAMUSCULAR TETRACYCLINE IN THE TREATMENT OF ACUTE GONORRHOEA IN THE MALE

\begin{tabular}{c|c|c|c|c|c|c}
\hline Dosage & $\begin{array}{c}\text { Total } \\
\text { Dose } \\
\text { (mg.) }\end{array}$ & $\begin{array}{c}\text { Number } \\
\text { of } \\
\text { Cases } \\
\text { Treated }\end{array}$ & $\begin{array}{c}\text { Number } \\
\text { of Cases } \\
\text { Followed- } \\
\text { up }\end{array}$ & Cured & $\begin{array}{c}\text { Fail- } \\
\text { ures }\end{array}$ & $\begin{array}{c}\text { Side } \\
\text { Reac- } \\
\text { tions }\end{array}$ \\
\hline $\begin{array}{c}\text { Single injection .. } \\
\text { 2 simultaneous in- }\end{array}$ & 100 & 8 & 6 & 0 & 6 & 1 \\
$\begin{array}{c}\text { jections of 100 } \\
\text { mg. . }\end{array}$ & 200 & 20 & 6 & 0 & 6 & 0 \\
$\begin{array}{c}\text { simultaneous in- } \\
\text { jections of 100 } \\
\text { mg. each re- } \\
\text { peated after 24 } \\
\text { hrs .. }\end{array}$ & 400 & 60 & 33 & 28 & 5 & 0 \\
\hline
\end{tabular}

Only the 45 adequately observed cases who received injections of intramuscular tetracycline were considered. Neither the six patients observed out of eight who received a $100-\mathrm{mg}$. injection nor the six observed out of twenty who received a total dose of $200 \mathrm{mg}$. responded to treatment. When the dose was increased to $400 \mathrm{mg}$., 28 (85 per cent.) out of 33 patients were cured.

The patients who responded favourably were cured rapidly, the thick urethral discharge disappearing within 24 hours.

Among the 88 patients receiving tetracycline, there was one allergic reaction to the drug manifested by moderate urticaria and slight oedema of the lips. This patient gave a history of severe allergic reaction to penicillin which had necessitated hospitalization. With this one exception, no toxicity 
of any nature was observed. About 40 per cent. of the patients complained of local pain at the site of injection. This pain lasted in some cases for 48 hours. On the other hand, there were patients who minimized the complaint of pain and found it no more severe than with other types of intramuscular medication with which they were familiar. Objectively there were no local signs of irritation, such as erythema, induration, or evidence of lesions at the sites of injection.

\section{Discussion}

Although this study involves a small number of cases it would appear that in adequate doses intramuscular tetracycline is effective in the treatment of acute gonorrhoea. The results indicate that $400 \mathrm{mg}$. is the minimal dose that should be used, and that larger doses may be more effective.

Intramuscular tetracycline thus lends itself to the treatment of gonorrhoea when parenteral medication is indicated.

\section{Summary}

Intramuscular tetracycline was used in the treatment of acute gonorrhoea in the male. Doses of $100 \mathrm{mg}$. and $200 \mathrm{mg}$. were found to be inadequate, but $400 \mathrm{mg}$. of the antibiotic cured 28 out of 33 patients ( 85 per cent.).

There was one mild allergic reaction in a patient who gave a history of severe allergy to penicillin. Approximately 40 per cent. of the patients complained of pain at the sites of injection.

This investigation was supported, in part, by a grant from the Lederle Laboratories Division of the American Cyanamid Company, Pearl River, New York.

\section{REFERENCES}

Marmell, M., and Prigot, A. (1954). Antibiot. and Chemother., 4,1117 .

- (1955). Int. Rec. Med., 168, 254.

Metzger, W. I., Marmell, M., and Prigot, A. (1954). Amer. J. Svph., 38, 480 . 